\title{
A Study on the Proper Treatment Time of Electronic Moxibustion - Focusing on the Skin Safety -
}

\author{
So Yun Park ${ }^{1,4 *}$, Ji Yong Hwang ${ }^{2 *}$, Byung Wook Lee ${ }^{3,4}$, Bong Hyo Lee ${ }^{2}$ \\ Departments of ${ }^{1} \mathrm{Herb} \&$ Pharmacology, ${ }^{2}$ Acupuncture, Moxibustion, and Acupoint, College of Korean Medicine, Daegu \\ Haany University, ${ }^{3}$ Department of Literature and Medical History, College of Korean Medicine, \\ Dongguk University, ${ }^{4}$ Dong-Je Medical
}

\section{전자뜸의 적정 시술시간에 대한 연구 -피부 안전성 중심- 박소윤 $^{1,4 \star} \cdot$ 황지용 ${ }^{2 \star} \cdot$ 이병욱,4 $\cdot$ 이봉효 ${ }^{2}$ 대구한의대학교 한의과대학 ${ }^{1}$ 본초약리학교실, ${ }^{2}$ 침구경혈학교실, ${ }^{3}$ 동국대학교 한의과대학 원전의사학교실, ${ }^{4}$ 동제메디칼}

Objectives : Electronic moxibustion was developed to overcome the weakness of conventional moxibution. However, in spite of many benefits, it also can not be entirely free from the concern of burning. This study was performed to investigate the proper treatment time of electronic moxibustion. Methods : Male sprague-Dawley rats weighing about $350 \mathrm{~g}$ were used. Animals were anesthetized with sodium pentobarbital and shaved on the abdomen or back. The full charged-electronic moxibustion device was placed on the shaved site and it was observed if there happened any adverse event after treatment. Results : At the temperatures of 41,43 , and $45^{\circ} \mathrm{C}$ there was no abnormal sign after moxibustion even in full time. However, at $47^{\circ} \mathrm{C}$, the safe treatment time was $3 \mathrm{~min}$. On the other hand, $49^{\circ} \mathrm{C}$ produced diverse adverse events even in $1 \mathrm{~min}$. Conclusions : Results of the present study suggest that the safe treatment time of electronic moxibustion is different according to the temperature. The most common adverse effect in this electronic moxibustion was the white spot and it is needed to observe whether there is any adverse event until $48 \mathrm{~h}$ after treatment.

Key words : electronic moxibustion, adverse event, white spot, blister, safety

\section{Introduction}

Moxibustion, one of the representative treatment tool of Korean medicine, prevents and treats diseases through heat stimulation at specific acupoints ${ }^{1}$. It not only relieve pain but also exerts a number of functions. Bao et al. has shown that moxibustion decreased inflammatory bowel disease questionnaire scores in Crohn's Disease2) and Li et al. demonstrated

\footnotetext{
Received March 1, 2018, Revised March 16, 2018, Accepted March 16, 2018

Corresponding author: Bong Hyo Lee

Department of Acupuncture, Moxibustion and Acupoint, College of Korean Medicine, Daegu Haany University, 136 Shincheondong-ro, Suseong-gu, Daegu

42158, Korea

Tel: +82-53-819-1828, Fax: +82-53-768-6340, E-mail: rjscjs31@hanmail.net

Corresponding author: Byung Wook Lee

Department of Literature and Medical History, College of Korean Medicine, Dongguk University, 123 Dongdae-ro, Gyeongju 38066, Korea

Tel: +82-54-770-2665, Fax: +82-54-770-2001, E-mail: omis@dongguk.ac.kr.

*Two authors equally contributed to this work.

This study was supported by the traditional Korean medicine R\&D program funded by the ministry of Health \& Welfare through the Korea Health Industry Development Institute(KHIDI)(HI17C0840).

(C) This is an open access article distributed under the terms of the Creative Commons Attribution Non-Commercial License (http://creativecommons.org/licenses/ by-nc/4.0) which permits unrestricted non-commercial use, distribution, and reproduction in any medium, provided the original work is properly cited.
} 
that moxibustion ameliorated visceral pain by downregulating the extracellular signal-regulated kinase, substance $\mathrm{P}$, and neurokinin-1 protein and mRNA expression in dorsal root ganglia ${ }^{3)}$. Also, moxibustion treated chronic atrophic gastritis by regulating energy metabolism in serum ${ }^{4)}$ and ameliorated the postherpetic neuralgia with herpes zoster through changing the protomics indexes ${ }^{5}$. In addition, moxibustion protected pulmonary fibrosis by downregulating TGF- $\beta 1$ and upregulating IFN- $\gamma$ cytokines at both mRNA and protein levels ${ }^{6}$ and prevented depressive symptoms during pregnancy or postpartum ${ }^{7)}$. Furthermore, heating had been suggested to be helpful for the treatment of disseminated cancer ${ }^{8)}$.

Nevertheless, moxibustion has weakness in that it needs ventilation system to remove the smog, it has possibility of burn or pain due to the difficulty of regulation of the intensity of fire ${ }^{9-12)}$, and it has some adverse effects of allergy or nausea ${ }^{13)}$. These weaknesses act as a reason why people avoid the moxibustion treatment. Indeed, the burn by moxibustion takes a major part in the medical disputes of Korean medicine $^{14)}$

Therefore, there have been a lot of efforts to solve these problems and recent researches that try to develop the electronic moxibustion are the representative cases of the efforts $^{9,15,16}$. Electronic moxibustion not really burns the moxa corn but produces heat stimulation by electrical device, and therefore, is benificial in that it is free from the problems of burning moxibustion. In addition, it is semipermanent and rarely needs to change parts.

However, it can not be said that the electronic moxibustion is perfectly safe from the possibility of burning because it is the same with burning moxibustion in the point of using heat stimulation to produce effectiveness ${ }^{17)}$.

Therefore, a research making an evidence to establish the safe treatment time in the moxibustion is urgently required and we conducted an animal research to investigate the safe treatment time that does not make an adverse effect. We expect this study can act as a preliminary data for the further studies and clinical studies.

\section{Materials and Methods}

\section{Animals}

Male sprague-Dawley rats(Daehan Animal, Seoul, Korea) weighing around $300 \mathrm{~g}(9$ weeks old $)$ at the start of experiment were used. Rats were kept in a animal room with the environment conditions of $12 \mathrm{~h}$ light-dark cycle(turn on at 7:00 a.m.), room temperature $\left(22 \pm 2^{\circ} \mathrm{C}\right)$, and humidity $(60 \pm 2 \%)$. They were allowed to freely access to the food and water. Following three to seven days of acclimatization period, animals were subjected to the experiments. Rats were treated under minimized stress cross over all of the experiments in compliance with the protocols approved by the Institutional Animal Care and Use Committee at the Daegu Haany University(DHU2017-057).

\section{Procedure}

After adaptation to the experimental environment, animals were anesthetized with intraperitoneal injection of pentobarbital $(50 \mathrm{mg} / \mathrm{kg}$ ) and were given shaving clearly on the back or abdomen. Then rats were placed on a surgery cotton pad and received the electronic moxibustion treatment during an assigned time. After moxibution, the electronic moxa was removed and it was checked whether there was any abnormal sign on the skin of treatment site.

\section{Electronic moxibustion}

Electronic moxibustion treatment was performed with the

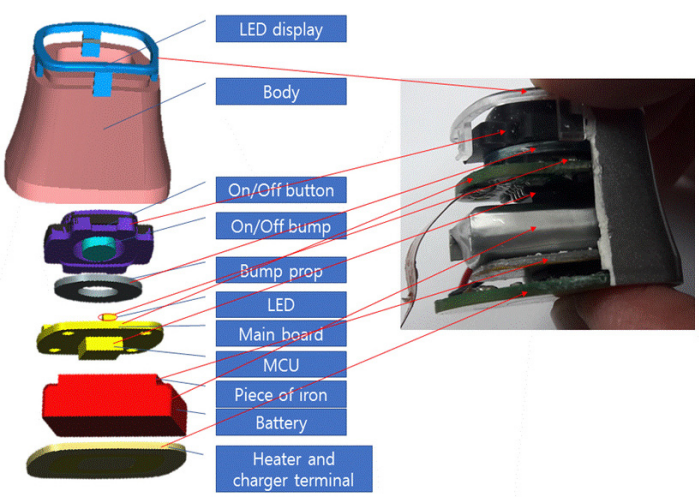

Fig. 1. Structure of the electronic moxa. 
'Cettum' device(Dong-Je Medical, Korea), one of the widely used invention(Fig. 1). The temperature had been set to 5 of $41^{\circ} \mathrm{C}, 43^{\circ} \mathrm{C}, 45^{\circ} \mathrm{C}, 47^{\circ} \mathrm{C}$, and $49^{\circ} \mathrm{C}$. The device was fully charged before starting experiments. When heating, the button equipped on the top was pushed then the temperature reached the set degree after $10 \mathrm{sec}$. Therefore, $10 \mathrm{sec}$ after pushing the start button, the moxa was placed on the shaved skin of back or abdomen of rat(Fig. 2A). At first moxibustion was performed at abdomen, and back was treated when abdomen showed no abnormal results even at full time. The full working time of each moxibustion was 28 min i.e. it turned off automatically after $28 \mathrm{~min}$. To prevent a space between the skin and bottom surface of moxa, the moxa was tightly contacted with holding by researcher however it was not strongly pushed.

\section{Evaluation of skin damage and criteria of safety}

After electronic moxibustion, it was checked whether this treatment induced an abnormal result on the skin of the site, including erythema, blister and spot. This observation was performed 5 times as following : immediately after treatment, $10 \mathrm{~min}$ after treatment, $20 \mathrm{~min}$ after treatment, $24 \mathrm{~h}$ after treatment, and 48 min after treatment.

It was defined as safe treatment when even one animal did not get any adverse event at the temperature.
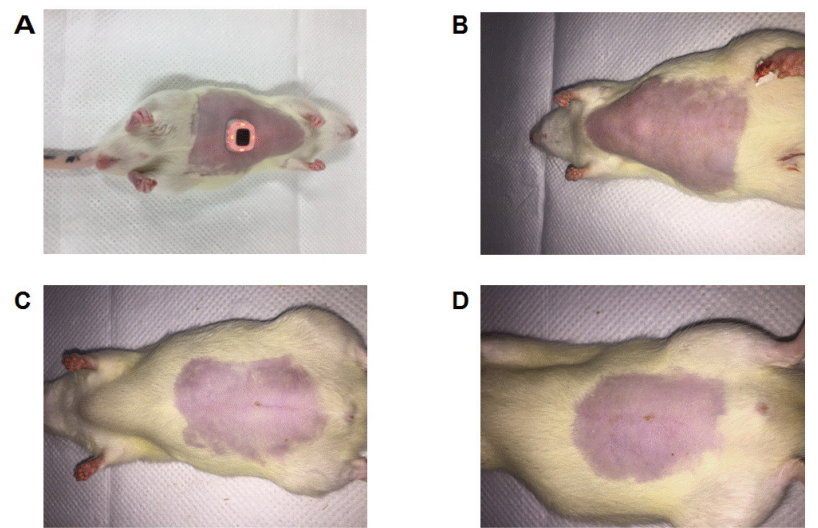

Fig. 2. (A) Actual treatment of the Electronic moxibustion. Results of the treatments at $41^{\circ} \mathrm{C}(\mathrm{B}), 43^{\circ} \mathrm{C}(\mathrm{C})$, and $45^{\circ} \mathrm{C}$ (D). There was no special adverse event on the skin.

\section{Results}

In $41 \sim 45^{\circ} \mathrm{C}$, there was no abnormal sign after moxibustion in full time of 28 min on the back as well as abdomen(Fig. 2B-D). When even checked after 48 h, no abnormal events were observed in these temperatures.

However $47^{\circ} \mathrm{C}$ moxibution produced some abnormal events. At first, 2 rats out of 6 showed slight erythema immediately after treatment, and after 24 h, 1 of these 2 and another 1 rats had white spot on their abdomen when treated for $28 \mathrm{~min}$. When the treatment time was shortened to 10 min, 1 out of 6 showed slight erythema immediately after treatment, and after $24 \mathrm{~h}$, blister was observed in this rat.

On the 9 min of treatment, 6 rats exhibited no event immediately after treatment however we observed white spot or blister in all of these 6 rats after $24 \mathrm{~h}$. In the treatment time of $8 \mathrm{~min}$, the same event with 9 min occurred in 2 out of 6 rats. When the treatment time was shortened to $7 \mathrm{~min}$, 2 rats showed erythema immediately after and these rats exhibited white spot after $24 \mathrm{~h}$. Additionally, the other 2 rats who had shown no event immediately after treatment had white spot after $24 \mathrm{~h}$.

In 6 min of treatment time, no event was observed immediately after however white spot appeared in 2 rats 24 $\mathrm{h}$ after(Fig. 3A). In $5 \mathrm{~min}$ of treatmet time, 2 rats showed erythema immediately after, however, they had no further abnormal event. Instead, the other 2 rats who had shown no
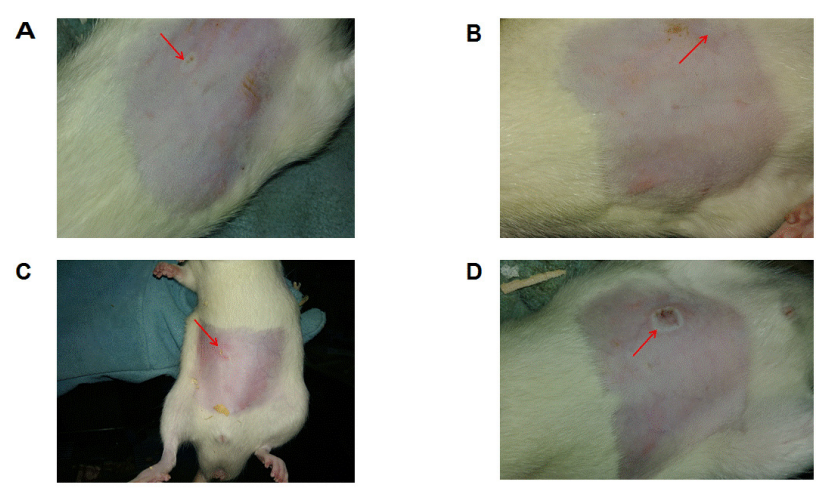

D

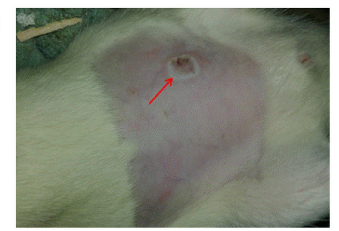

Fig. 3. Results of the treatments at $47^{\circ} \mathrm{C}$ for $6 \mathrm{~min}(\mathrm{~A}), 5 \mathrm{~min}$ (B), and $4 \mathrm{~min}(C)$ and at $49^{\circ} \mathrm{C}$ for $1 \mathrm{~min}$ (D). There were adverse events of white spot (A and B), blister (C), and white spot, blister, and erythema (D). 
event exhibited white spot after $24 \mathrm{~h}$ (Fig. 3B). In 4 min, all of the 4 rats had erythema immediately after and 2 of them had white spot or blister(Fig. 3C).

When shortened to $3 \mathrm{~min}$, the $47^{\circ} \mathrm{C}$ moxibution produced no abnormal event immediately after, $24 \mathrm{~h}$, and even $48 \mathrm{~h}$ later in all of 7 rats.

In $49^{\circ} \mathrm{C}$ abnormal events of white spot, blister, or erythema were observed even $1 \mathrm{~min}$ of moxibustion(Fig. 3D).

\section{Discussion}

Nowadays, diverse modern inventions has been being used in Korean medicine. Electronic moxibustion, one of the modern intervention, has some benefits as following. First it is more easy to munipulate, second it does not need to equip a special ventilation system due to not producing smog, third it can be used semipermanently, and forth it has less possibility of burning.

However in spite of this much convenience, electronic moxibustion can not be free from the possibility of burning. Therefore we have conducted the present study to find what the maximum of treatment time is for the safe electronic moxibustion at each temperature is.

At the temperatures of $41 \sim 45^{\circ} \mathrm{C}$, there was no adverse event even in the full time treatment of $28 \mathrm{~min}$.

However in the temperature of $47^{\circ} \mathrm{C}$, there happened adverse events of erythema, white spot, and blister. Even in the treatment time of $4 \mathrm{~min}$, this temperature produced those results and 3 min treatment proved not to produce these events. These results mean that the safe time when using $47^{\circ} \mathrm{C}$ was no more than $3 \mathrm{~min}$. Thinking that until $45^{\circ} \mathrm{C}$ there happened no adverse effect even in full time, it seems that there is a huge gap between $45^{\circ} \mathrm{C}$ and $47^{\circ} \mathrm{C}$ that the safe time was suddenly shortened. Therefore, it seems to be needed to set the temperature of $46^{\circ} \mathrm{C}$ to investigate the safe treatment time in more detail.

Also, it is needed to further investigate whether $41^{\circ} \mathrm{C}, 43^{\circ} \mathrm{C}$, and $45^{\circ} \mathrm{C}$, are worth of electronic moxibustion. Because those temperatures made no results even in full time, there may be a possibility that these temperatures are not able to heat enough to act as moxibustion.

These results are not parallel with the other studies. At first Jang et al. ${ }^{18)}$ demonstrated that temperature of above $42^{\circ} \mathrm{C}$ is clinically meaningful. However this temperature had no change on skin even in full time of $28 \mathrm{~min}$ in the present study implying a possibility of unusefulness. Also Adriaensen et al. ${ }^{19)}$ demonstrated that thermal stimulation with $44.5 \sim 46.5^{\circ} \mathrm{C}$ activated A-fibre mechanoheat nociceptors(AMH) when performed on human skin. However our results revealed that $45^{\circ} \mathrm{C}$ produced no change on the skin. These differences might be caused from the difference of moxibustion method. The electronic moxibustion used in the present study might be less hot to the skin than direct or indirect moxibustion by burning of moxa corn. Otherwise, the studies perhaps did not take the adverse event caused on skin into consideration. Nevertheless these differences appear to need to be further investigated.

In addition, some animals who showed adverse results $24 \mathrm{~h}$ after treatment had exhibited no events immediately after. Therefore it is necessary to observe carefully if there is any adverse events at least until $24 \mathrm{~h}$ after treatment although there happened nothing immediately after. Indeed, Chae et al. demonstrated that electronic moxibustion produced erythema $24 \mathrm{~h}$ after treatment even in a short treatment time of $2 \min ^{17}$.

This study aimed to investigate the proper treatment time based on the skin safety. Therefore, even if any adverse event was observed it was defined not safe. However it would be better if quantify the severity of adverse events using histophysiological methods and investigate the relation between treatment time and severity of adverse effects in the future studies.

In summary, the present study performed to investigate the safe treatment time at each temperature has found that the relatively low temperatures of $41^{\circ} \mathrm{C}, 43^{\circ} \mathrm{C}$, and $45^{\circ} \mathrm{C}$ can be used in full time of $28 \mathrm{~min}$. However, $47^{\circ} \mathrm{C}$ must be used within the maximum of $3 \mathrm{~min}$. Furthermore $49^{\circ} \mathrm{C}$ seems not to be proper as electronic moxibustion because this temperature produced adverse event even in $1 \mathrm{~min}$. 


\section{Acknowledgements}

This study was supported by the traditional Korean medicine R\&D program funded by the ministry of Health\& Welfare through the Korea Health Industry Development Institute(KHIDI)(HI17C0840).

\section{References}

1. The acupuncture and moxibustion medicine. Committee on the compilation of textbook for acupuncture and moxibustion. Jipmoondang publishing company. 2012 : 328, 329.

2. Bao C, Wang D, Liu P, Shi Y, Jin X, Wu L, et al. Effect of electro-acupuncture and moxibustion on brain connectivity in patients with Crohn's disease: a resting-state fMRI study. Frontiers in human neuroscience. $2017 ; 11: 559$.

3. Li ZY, Yang YT, Hong J, Zhang D, Huang XF, Wu LJ, et al. Extracellular signal-regulated kinase, substance P and neurokinin-1 are involved in the analgesic mechanism of herb-partitioned moxibustion. Neural Regen Res. 2017 ; 12(9) : 1472-8.

4. Liu CC, Chen JL, Chang XR, He QD, Shen JC, Lian LY, et al. Comparative metabolomics study on therapeutic mechanism of electro-acupuncture and moxibustion on rats with chronic atrophic gastritis(CAG). Scientific Reports. 2017 ; 7(1) : 14362.

5. Gang F, Pan C, Haicheng W, Hongrui Z, Jiang Z, Chen L. Effect of Zhuang medicine medicated thread moxibustion on protomics in serum of postherpetic neuralgia patient with Herpes zoster. Pakistan journal of pharmaceutical sciences. 2017 ; 30(3(Special)) : 1063-7.

6. Cheng L, Li R, Zhou M, Li F, Chang Q, Li C, et al. Moxibustion has a positive effect on pulmonary fibrosis: an alternative approach. African journal of traditional, complementary, and alternative medicines. 2017 ; 14(2) : 125-9.

7. Suzuki S, Tobe C. Effect of acupressure, acupuncture and moxibustion in women with pregnancy-related anxiety and previous depression: a preliminary study. Journal of clinical medicine research. $2017 ; 9(6): 525-7$.

8. Giovanella BC, Lohman WA, Heidelberger C. Effects of elevated temperatures and drugs on the viability of L1210 leukemia cells. Cancer research. $1970 ; 30: 1623-31$.
9. Cha JY, Myoung HS, Cho SP, Lee KJ. Development of deep-heating stimulation system for substituting the heat effect of moxibustion. Journal of the institute of electronics engineers of Korea. 2009 ; 46(6) : 50-7.

10. Marquardt MF, Pollak S, Schmidt U. "Cigarette burns in forensic medicine”. Forensic Science International. 2008 ; $176(2): 200-8$.

11. Bensoussan A, Myers SP, Carlton AL. "Risks associated with the practice of traditional chinese medicine”. Archives of family medicine. 2000 ; 9(10) : 1071-8.

12. Koh HK, Ahn BC, Park DS, Kang SK, Kim CH, Cheon YS, et al. The experimental study on combustion characteristics of the moxa-combustion in the skin model, agar. The Journal of Korean acupuncture \& moxibustion medicine society. 1999 ; 16(3) : 155-77.

13. Park JE, Lee SS, Lee MS, Choi, SM, Ernst E. Adverse events of moxibustion: a systematic review. Complement Therapies in Medicine. 2010 ; 18(5) : 215-23.

14. Requirement of compensation for damages following burning after moxibustion. The editorial department of Korea consumer agency. Casebook for adjustment of medical disputes. 2012 ; 12 : 575-83.

15. Bae JH, Song SJ, Kim HJ, Kim KB. Study of focusing characteristics of ultrasound for designing acoustic lens in ultrasonic moxibustion device. Journal of the Korean Society for Nondestructive Testing. 2015 ; 35(2) : 134-40,

16. Yang SY, Huh W, Kim JK, Park YB. Thermal Stimulation System for Meridian point. Korean society for electronics and engineers conference 2001.

17. Chae H, Noh SH, Kim YR, Jung HR, Ha HY, Kim KH, et al. Preliminary study for the comparison of the skin temperature changes by the combustible moxibustion and the electronic moxibustion divece. The Journal of Korean acupuncture \& moxibustion medicine society. $2012 ; 29(3): 1-8$.

18. Jang MK, Yoon EH, Jung CY, Byun H, Kim EJ, Kim KH, et al. Credibility of a newly developed sham moxibustion. The Journal of Korean acupuncture \& moxibustion medicine Society. $2010 ; 27(1): 117-27$.

19. Adriaensen H, Gybels J, Handwerker HO, Van Hees J. Response properties of thin myelinated (A-delta) fibers in human skin nerves. Journal of Neurophysiology. 1983 ; 49 : 111-22. 